\title{
Identification of factors influencing patient satisfaction with orthopaedic outpatient clinic consultation: a qualitative study
}

\author{
Stuart Waters ${ }^{1,2}$ \\ Stephen J Edmondston ${ }^{3}$ \\ Piers J Yates ${ }^{4}$ \\ Daniel F Gucciardi ${ }^{2}$
}

${ }^{1}$ Physiotherapy Department, Fremantle Hospital
${ }^{2}$ School of Physiotherapy and Exercise Science, Curtin University
${ }^{3}$ Shenton Park Physiotherapy Clinic
${ }^{4}$ Orthopaedic Surgery Department, Fiona Stanley Hospital, Perth Western Australia

Corresponding Author:

Stuart Waters

c/o Physiotherapy Department

Fremantle Hospital

Fremantle WA 6160

Email: swatshenton@gmail.com 


\begin{abstract}
Background: In recent years, new models of health service delivery in orthopaedic outpatient clinics, included physiotherapists working in orthopaedic triage roles, have become increasingly common. Evaluation of patient satisfaction with orthopaedic clinic services is dependent on an understanding of factors influencing patient satisfaction in this clinical context.
\end{abstract}

Objectives: The objective of this study was to identify the factors influencing patient satisfaction with orthopaedic outpatient clinic services.

Study Design: A cross-sectional, qualitative design including focus groups and interviews.

Methods: Interviews and groups sessions were undertaken across 36 participants representing patients, health professionals and clinical support staff in an orthopaedic outpatient clinic. Interviews and focus groups provided a rich narrative which was subjected to a process of thematic analysis.

Results: The analysis indentified seven themes influencing patient satisfaction with orthopaedic clinic assessment. These themes were clinic waiting time, clinical contact time, trust, empathy, communication, expectation and relatedness.

Conclusions: Understanding factors influencing patient satisfaction is important to inform organisational and clinical processes that aim to foster high levels of patient satisfaction. Clinician awareness of the interpersonal issues which dominate stakeholders' perspectives of patient satisfaction may improve the patient experience and potentially foster patient behaviours toward a therapeutic advantage. An understanding of these factors in the context of orthopaedic clinics is also important in the development of questionnaires designed to evaluate patient satisfaction with health service delivery.

Keywords: Orthopaedic, Patient Satisfaction, Qualitative 


\section{INTRODUCTION}

There is considerable and increasing demand for orthopaedic services arising from an ageing population and increasing patient to surgeon ratio (Royal Australian College of Surgeons, 2011). One of the strategies used to ensure timely access to orthopaedic services has been the implementation of orthopaedic triage clinics where physiotherapists evaluate patients referred for orthopaedic surgery review. In this context, physiotherapists take on the traditional role of the orthopaedic surgeon in the preliminary evaluation of patients.

There is evidence that orthopaedic triage by physiotherapists is effective from a health services management perspective. Previous studies have shown that both physiotherapyorthopaedic triage clinics and surgeon-led clinics produce similar clinical outcomes in relation to both patient evaluation and management (Edmondston et al., 2011; Desmueles et al., 2013). There is also evidence that this approach is an effective strategy to manage orthopaedic waitlists (Napier et al., 2013). Despite these encouraging results regarding the effectiveness of physiotherapy orthopaedic triage, there has been limited evaluation of patients' satisfaction with this experience, or acceptance of this model of care.

Patient satisfaction has been proposed as being independent to clinical outcome when evaluating the quality of clinical services. (Hudak and Wright, 2000; Butler and Johnson, 2008). Patient satisfaction is increasingly being evaluated by health service administrators to assess both clinician and institutional performance. The evaluation of patient experience forms a significant contribution to Standard 2 of the National Safety and Quality Health Service (NSQHS) standards relating to consumer engagement in Australian hospitals (ASQHC Standards, 2012). 
The evaluation of patient satisfaction with orthopaedic triage clinics has been limited to global assessments of satisfaction (Oldmeadow et al., 2007) or using modified generic surveys with limited validity in relation to orthopaedic assessment or orthopaedic triage (Kennedy et al.,2010). Alternatively, researchers have employed proxies such as quality of care, with the assumption that these measures are directly and proportionally related to satisfaction (Samsson and Larsson, 2015). Consequently, the relevance of these assessment tools and the degree to which they measure patient satisfaction with orthopaedic clinic services is uncertain. As an important first step towards the development of a context-specific understanding of this construct, the purpose of this study was to examine key stakeholders' perspectives of patient satisfaction in the context of orthopaedic outpatient clinics. The domains of patient satisfaction identified can then be used in the development of a purpose-specific patient satisfaction questionnaire.

\section{METHOD}

\section{Design}

The study used a cross-sectional, qualitative design including focus groups and 1-1 interviews Methodology within the focus groups was guided by Patton 2015.

\section{Participants}

Participants were recruited from staff and patients at Fremantle Hospital (FHHS). Participants were recruited using criterion-based purposive sampling to source individuals who share a common experience and could provide unique perspectives of the concept (i.e., patient satisfaction) and experience (i.e., orthopaedic clinic services) (Freeman, 2014). Guided by the concept of data saturation, participants were recruited on a rolling basis until no new and 
relevant information was reported (O'Reilly \& Parker, 2012). Thus, there was no predetermined figure regarding the number of different types of participant groups nor relative proportions of these individuals. The key here was to ensure that there was adequate depth and breadth of information with regard to the research question (O'Reilly \& Parker, 2012). Focus groups offer access to shared understandings and perspectives, as well as group interactions that can promote unique insights that may not be gathered in 1-1 interviews. In contrast, 1-1 interviews offer an in-depth insight into personalized stories and perspectives of patient satisfaction within the context of clinical orthopaedic assessment that people may not feel comfortable sharing in group settings (Powell and Single 1996). The decision to conduct a 1-1 interview or focus group was guided by pragmatics of the research context, as not all participants were available to make a group time (i.e., patients, registrars, consultants). Clinicians (orthopaedic surgeons, orthopaedic registrars, clinic nurses, physiotherapists), support staff (receptionists), patients, volunteers and a consumer advisory group (CAC) were represented in the study. The CAC group represents consumer advocacy with the hospital. The input from the CAC represented the sum total of attendance to a CAC meeting within the hospital. The CAC represents a unique view of the patient as a consumer of health services, reviewing complaints and pursing compliance with policy and standards set around patients.

The patient group was drawn from consecutive individuals presenting with non-acute conditions attending the FHHS orthopaedic outpatient clinic for follow-up assessment on 2 clinic days. Table 3 provides a profile of the patient cohort included within the focus group.

All patients completed initial assessment and provided informed consent to participation. All participants were approached in person by the lead researcher and were aged over 18 years. Patients whose communication skills did not allow comprehension of the consent form or the 
ability to complete a written survey were excluded. In total, 18 individual interviews were undertaken with 10 patients, 4 consultants, 4 registrars and 1 reception staff. Additionally, 4 focus groups were undertaken, one each for physiotherapists, nurses, volunteers and CAC. Table 1 profiles characteristics of the focus group participants whilst Table 3 outlines diagnostic profiles of the patient group.

\section{Data collection}

Participant interviews and focus group discussions were conducted over an eight week period. Focus group sessions ranged from 20-45 minutes, whereas 1-1 interviews ranged from 15-25 minutes. Both interviews and focus groups were conducted by the lead researcher and guided, but not constrained, by semi-structured interview questions (Table 2). All interviews and focus group discussions were audio recorded.

All interviews and group sessions were carried out by the lead investigator. The use of the lead investigator is proposed as a key strength of the methodology in allowing the use of contextually relevant terminology, and minimised the need to define key terms or jargon thereby sustaining positive flow in the discussion. As a clinician, the lead investigator could utilise background knowledge of the context and research question developing rapport with participants. The lead investigator is known professionally to the clinical and professional contributors within the focus groups.

Any potential bias arising from the role of the lead investigator in leading the discussion is minimised by several strategies. First, the lead researcher used the same semi structured format of questions for each session. Second, the lead investigator and the supervising investigator engaged in critical review meetings of the interviews at regular intervals during 
data collection, particularly earlier on in this piece, discussing assumptions and biases and how they may have influenced questioning and probing of participants both in terms of direction and content (Liamputtong \& Ezzy 2005).

\section{Ethics}

This study was approved by the WA Department of Health Human Research Ethics Committee (Approval No: 14/22) and the Curtin University Ethic committee (Approval No; HR 96/2014). All participants within this study offered informed consent.

\section{Data analysis}

Audio recordings of interviews were transcribed verbatim by a professional transcription service. Minor spelling and grammatical errors were edited by the lead investigator on receipt of the transcript. All participants were given the opportunity to review and revise their transcript prior to data analysis.

Data was analysed thematically using an inductive approach whereby the data itself served as the primary source of information regarding emergent codes and themes. The process of thematic analysis was informed by Braun and Clarke (2006) who suggested a series of phases in thematic analysis which include familiarization, coding, searching, and reviewing, prior to naming and defining. The transcriptions were initially reviewed independently by the two lead investigators with comments and analysis of themes recorded as comments in the transcript, permitting familiarization with the data and preliminary codes. The two lead investigators held a series of meetings to review the emergent themes, ensuring agreement. A third investigator was utilised where the initial process did not produce consensus. A summary was 
then compiled with definitions of the identified themes, matched against quotes from the transcript and additional notes of thematic interpretation.

\section{FINDINGS}

From a sample of 41 eligible participants, 36 individuals were included in the study. A profile of participants and the proportional input of each group into the transcription are shown in Table 4. All consultants, registrars, patients and front desk staff were interviewed on a 1-1 basis as it was not feasible to bring these participants together at a single point of time. Physiotherapists, nurses, volunteers, and Consumer Advisory Committee (CAC) were interviewed within group settings $(\mathrm{N}=4)$, where group numbers ranged from three to five participants.

\section{Theme 1: Clinic Waiting Time}

One of the most commonly discussed themes centred on the time taken from arrival in the clinic to consultation with the clinician. Participants discussed this theme in a variety of ways. It was evident that clinicians and clinical support staff were aware of, and acknowledged, the importance of clinical waiting time for patient satisfaction.

"It's actually waiting time: that is our biggest failure." [female nurse]

"I think the key things are how long they've waited to come in the first time, how long they've been in the waiting room, because I think it's very hard to have a satisfied patient who's sat there for four hours before they've seen you, they're never satisfied." [male consultant] 
A consultant identified the flow on effect of extended clinic waiting times.

"People who wait for three hours in clinic will almost invariably come in and have more issues. They'll have more problems and I find more complications than those who get seen swiftly and get moved sort of efficiently and timely. " [(male consultant]

There was evidence of patient awareness of clinic efficiency as a factor influencing waiting times.

"The two clinic clerks had the shutters down, it was 8:30 in the morning and they're yabbering away and there's a string of people lining out the doorway. Already, people were going on about how they were stressed about waiting” [male patient].

\section{Clinical Contact Time}

Patients often raised the issue of having sufficient time with the clinician, and the impression of being managed or rushed through the appointment. In these instances, patient satisfaction with the clinical experience was low.

"If you're feeling like you're rushed in and out, I don't think you develop the trust as much. I don't think you feel like they're maybe going to do the best work for you." [female patient]

"I think from my point of view, I've got to have enough time because it's very hard to make someone satisfied if you're on call and you've received thirty phone calls and your phone keeps ringing. People need to be engaged, you have to have interest in what they've got to say. " [male registrar] 
Clinicians acknowledged time pressures within clinics and the difficulties with patients when expectations of the consultation were not fulfilled.

"So time pressures, I think, is the biggest issue, because you don't have time to listen to everyone's problems; and if you listen to what they have to say, then quite often you can sort things out rather than them stewing on it for two weeks and come back and it's becoming a mountain. " [female registrar]

Patient awareness of time spent within clinic was also acknowledged by front desk reception staff.

"I think the main problem is the amount of people who are waiting to come in for an appointment, but in saying that, by the time they come, they are generally happy to be here. I think the way to improve is more clinic time with the doctors" [female receptionist]

\section{Empathy}

The focus group and interviews supported the notion of empathy as an influential factor for patient satisfaction. Within this context, empathy was described as adopting the perspective of another person in order to understand their beliefs and feelings, and expressing this understanding positively through interpersonal interactions (e.g. communication). Empathy appeared to reinforce interpersonal aspects of the clinical interaction and was closely associated with caring behaviors. Patients in particular, described the importance of empathy within their experience of clinical assessment. 
"There was an issue being lifted off the emergency bed onto the ward bed and it really, really hurt. The nurse said with all orthopaedics it's nice if you have a small pain and it's hurting. It was as if it didn't matter. " [female patient]

"I thought the nurses were terrific and very empathetic." [female patient]

The importance of empathy was also reinforced by the health care providers.

"Often I hear of people that don't examine their patients and just look at scans and decide to treat them in a particular way and that doesn't make patients feel good. You need to take time to have some empathy, compassion, those sorts of things." [male registrar]

"It's as little as something as just being quite personable to someone, like saying hello, sit down, and just turning on that element....Okay, and then there would be people that are actually are caring and it's just small things like that you appreciate." [Female physiotherapist]

\section{Communication}

It was clearly evident amongst the participants that communication is an important consideration for patient satisfaction. Within this context, communication encompassed a delivery style that enhanced the exchange of information between the practitioner and client, and maximised clients' comprehension of the content of the information. The narrative data offered evidence that good communication implies sufficient interaction and input from both parties. Patients also inferred that communication was fundamental to feelings of connectedness and inclusion. 
"I suppose you come out with a more positive attitude. If you have a surgery done, and he spends $x$ amount of time and says in layman's terms that you actually understand, then you walk away and think, "Oh yeah well yeah." You're already in a positive frame of mind." [male patient]

"Clear communication, so they know what to expect, when they're coming, what's happening afterwards. I don't think we can really to go to every clinician and say, you know, be more friendly. Everyone's got their own style. It's about clear communication. " [female patient]

Clinicians also discussed communication as underpinning good clinical practice and patient satisfaction.

"I see a lot of patients privately for second opinions where I see a lot of them where they've been given perfectly good advice. They've actually had a perfectly good assessment in terms of advice and treatment options. They're very unsatisfied with service they've had because they haven 't felt they've been communicated with or listened to properly. '[male consultant]

The importance of communication was recognised by the CAC.

"One of the concerns is communication, but it generally seems to be, if I'm reading the reports we've got correctly, more the doctors than the nurses. I'm merely backing up what Mary's saying that on a nurse level, the interpersonal skills are good. On a doctor level, goodness knows why ... Well, you can only imagine why; pressure, and sometimes their attitudes I guess. [Female committee member]" 
Volunteer group acknowledged the role of communication in including patient within the clinical process.

"No. If you're sitting there for half an hour or more, and then nobody comes out and says to you, "I'm sorry Mrs. Co, you're going to have to be a bit longer." Why can't they do that? Why do they have to sit there and sit behind their little counter, or sit behind the door, and not come out and say? I know they're busy. Everybody is. But surely they could pop their head out the door and say, I'm sorry, I'm going to be a bit longer. Would that hurt?" [female volunteer]

\section{Expectation}

The role of expectation influencing levels of patient satisfaction was clearly identified by the participants. The issue of expectation was identified largely by clinicians, where the central issue appeared to be patient dissonance where clinicians were unable to meet expectation.

"That's the kind of patient that comes in expecting an unrealistic expectation that you can't achieve, you can't do anything about it, and they are not gonna be happy whatever you say. There's times when that happens and there's nothing you can do about it." [male registrar]

A registrar recalled an experience as a patient.

"I didn't feel like he had perhaps evaluated the problem to the extent that maybe as a medical student, which I was then, I would expect him to. He recommended an operation on the first occasion despite the fact that I ended up not needing an operation at all." [male registrar] 
Clinicians identified that expectations often arise from information provided by the referring doctor. Potentially, this expectation is developed by the actions of referrers seeking to validate their own actions of transferring care.

"The GP who refers them may give them an unrealistic expectation via we'll send you to the orthopod who will fix your problem, which is rarely the case." [male consultant]

\section{Trust}

Patient satisfaction was said to be underpinned by the degree of trust in the healthcare provider. Trust was defined as an optimistic acceptance that presentation to a clinical service will potentially produce a benefit for the patient. One consultant identified the ritualistic nature of the signing of the consent as inferring trust:

“.... and in reality the consent form is really a form that says I trust you. The important part is chatting away and telling what the form is really, basically I recognise that you know what you're doing and you will try your best for me and in my circumstances you would be doing the same." [male consultant]

Patients identified trust as a central theme reflecting vulnerability in regard to a lack of knowledge or alternatives to solve their issue. Some patients referred to trust assumed by association to institution or role.

"If I met them before the operation and I don't recall doing so, I think perhaps someone may have come up and say "We're part of the team" but I'm just in the wash of painkiller so you just trust. I mean I'm been brought up to trust office and trust the decisions and advice." 
[female patient]

\section{Relatedness}

The extent to which a patient feels connected to, respected or understood by the clinician was discussed as an important factor for patient satisfaction. Patients, in particular, referred to being respected and validated as an individual with inference to an interpersonal connection or bond. Respect and validation were discussed in a variety of ways by patients.

"It's an act of respect, if someone introduces themselves to you, it's actually that they actually respect you enough to let you know who they are." [female patient]

"I'm laying there on the bed and people are in a circle there and they're all talking about me, but no one's talking to me". That's the impression that people get, so you turn off. It's the major thing with communication, to be able to create that link in the first place." [female patient]

"I was going to say, more like a face to face thing. I could look at their face and think, well I knew that he was actually taking me seriously. It's just like any anyone actually you can tell if you have been validated." [male patient]

"And you've got that connection because you put your trust in him when you had the operation. But then you get this other guy who you've never seen before to assess the leg. It's like you're in the process with the public system" [male patient] 
A summary of themes identified with representative narrative is contained in Table 5

Table 5

\section{DISCUSSION}

Several of the themes reported by participants in this study are consistent with recent literature, including the importance of clinic waiting time (McMullen and Netland, 2013), clinical time (Kong et al., 2007), communication (Hush et al., 2011), empathy (Pollak et al., 2011), expectation (Noble et al., 2006) and trust (Chang et al., 2013). These similarities suggest that there are aspects of the clinical experience that appear consistent across contexts and patient groups. Such issues would therefore be important to inform organisational and clinical processes that aim to foster high levels of patient satisfaction. By proportion, however, it is interpersonal issues that dominated key stakeholders' perspectives of patient satisfaction. This finding is consistent with previous research regarding patient satisfaction (Samsson and Larsson, 2015).

\section{Clinic environmental factors}

Clinical contact time was identified in the present study as an important theme in patient satisfaction. Patient contact time is, however, subjective and potentially influenced by differences in perception, experience and interpretation (Klitzman, 2007). Despite the impression that medical consultation time has reduced over time, there is evidence that this perception may not be the case (Druss and Mechanic, 2003).

Clinical waiting time has been identified by other authors examining factors influential to patient satisfaction. Ware and Hays (1988) refined the earlier work of Ware et al (1983) to develop the Visit Specific Questionnaire (VSQ) and the VSQ-9 which included clinic wait 
time as a factor or domain. The VSQ-9 has been a widely referenced survey tool and has been used a basis for modified tools in examining patient satisfaction in orthopaedic triage clinics (Kennedy et al 2010, Desmueles et al 2013). Although clinic waiting time was identified in as influential, other studies have suggested that its effect can be moderated through the quality of the subsequent clinical experience. (Anderson et al., 2007).

\section{Interpersonal factors}

The majority of themes reported by participants in this study concerned interpersonal factors. In particular, empathy was identified as having a significant impact on patient satisfaction. Pollak et al., 2011 reported that behaviors of clinician empathy were associated with autonomy support and higher levels of satisfaction. Hojat et al., (2010) confirmed a significant association between empathic behaviors by physicians and patient satisfaction. Whilst empathy is an important factor for patient satisfaction, limitations regarding the reliable and valid measurement of this construct mean it may be difficult to quantify in practice (Kelm et al., 2014).

Communication appears to underpin the concept of the patient-centred management (Bertakis and Azari, 2010) and is fundamental in developing the clinical alliance or bond (Ackermann and Hilsenroth 2003, Cooper et al., 2008). Although the exchange of information is critical to the process of clinical assessment, patient responses to the level and type of exchange may vary. Cooper et al., 2008 found that some patients did not want to be consulted in regard to their management options, but would rather rely on the clinician to determine the preferred management plan. For participants in the current study, good communication occurred when clinicians explained sometimes complex issues in a way that they could understand. Collectively, these findings suggest that individual patients may have different preferences 
with regard to the amount of information received and type of communication from their clinician.

Expectation is derived from a patient's existing beliefs and attitudes regarding the experience and outcome of the clinical consultation. The findings of the current study are consistent with past work that has identified the importance of expectation to patient satisfaction (Hills and Kitchen, 2007a, Noble et al., 2006). Since these beliefs and attitudes are created and sustained by a cognitive process (Thompson and Sunol, 1995), the process by which patients rationalise expectation and experience can potentially influence satisfaction with the consultation. Although the relationship between expectation and satisfaction has been established, it remains unclear whether the association is purely linear. For example, higher expectations of service do not automatically translate to a negative impact on satisfaction (Knight et al., 2010). The nature of expectation as an ongoing cognitive process may explain differences in association with satisfaction. It is possible that as the experience of the patient widens and interpersonal aspects between clinician and patient develop (through trust, relatedness, and communication), dissonance through expectation and experience may be less likely. Thus, it is important that clinicians attempt to understand and address patients' expectations regarding the clinical assessment (Noble et al, 2006).

In the present study, trust has been identified as a primary driver of patient satisfaction with clinical services (Chang et al., 2013, Alrubaiee and Alkaa'ida, 2011). Trust may also influence some patient behaviors benefiting the therapeutic process such as willingness to seek care (Trachtenberg et al., 2005), reveal sensitive information (Hall et al., 2002) and adhere to treatment regimes (Trachtenberg et al., 2005). Trust is also conferred by association to an institution or role/profession (Hall et al., 2002). Rhodes et al. (2015) observed trust 
could be translated to professional roles when continuity of care with an individual was not possible. Hall et al (2001) infers a shifting balance between trust through association and expectation, and trust derived through experience.

Relatedness is hypothesized to represent a basic psychological need that must be satisfied for people to experience positive development and outcomes (Ryan and Deci, 2000). In the context of health services, satisfaction of one's need to feel related to others will enhance the patient experience, satisfaction and motivation (Ng et al., 2012). Murray et al., 2015 found that physiotherapists trained in communication skills that can satisfy the need for relatedness were more able to support the needs of patients with chronic low back pain. Relatedness also appears to share parallels with the concept of the therapeutic alliance or bond (Del Re et al., 2012). Central to this alliance is the formation of an affective bond between therapist and patient (Del Re et al., 2012). A positive therapeutic alliance has been associated with improved satisfaction and clinical outcomes (Hall et al., 2010).

This study has some limitations in regard to the themes identified. Firstly, it was a single site study and subject to practices and culture at one hospital. Countering this to some degree is that many of the professionals involved within the study practice across multiple sites within the area health network both publically and privately.

There is also the question of whether the clinical background of the patient group would bias the nature of the responses collected with the study. Patient data is intended to reflect individual experience within an orthopaedic clinic setting across. Research suggests that whilst socio-demographic factors effects were discernible, patient satisfaction was influenced over a wider array of factors rather than one dominant patient characteristic (Hall \& Dornan 
1990). Age (McKinnon 2001) and chronicity (Hill \& Kitchen 2007b) are recognised as more consistent influences on level of patient satisfaction. Pereneger (2004) suggests that any attempt to control for these elements is problematic, in that health care is likely to be individualised, adjusting for the very patient characteristics that are being controlled for. Therefore, again, whilst it is prudent to profile the characteristics of any surveyed group, the influence of many of these factors remains uncertain.

The results of this study emphasise the importance of interpersonal factors influencing patient satisfaction with orthopaedic outpatient clinic services. These factors are important for health administrators to inform service improvement and for clinicians to consider when reflecting on patient management. By understanding how these themes influence the therapeutic process clinicians may able to align both perception and patient behavior to clinical advantage. Further work is required to integrate the themes identified in this study into a validated questionnaire to evaluate patient satisfaction with orthopaedic outpatient clinic services.

The use of a grounded phenomenological approach (Petty et al., 2012) to examine the patient experience of orthopaedic services offers key insights that could be used to shape and teach practitioner behaviours. Consideration of these perspectives may also avoid or alter paternalistic approaches to clinical practice (Thompson et al., 2014) 



\section{REFERENCES}

Ackerman SJ, M. J. Hilsenroth MJ. A review of therapist characteristics and techniques positively impacting the therapeutic alliance. Clin Psych Rev 2003;23:1-33.

Alrubaiee, L., \& Alkaa'Ida, F. (2011). The Mediating Effect of Patient Satisfaction in the Patients' Perceptions of Healthcare Quality - Patient Trust Relationship. International Journal of Marketing Studies, 3(1), 103-127.

Anderson RF, Camacho, Balkrishnan R. Willing to wait? The influence of patient wait-time on satisfaction with primary care. BMC Health Serv Res 2007;28:7-31-36.

Bertakis KD, Azari R. Determinants and outcomes of patient-centered care. Patient Educ Couns 2010;85:46-52.

Braun V, Clarke V. Using thematic analysis in psychology. Qual Res Psych 2006;3:77-101.

Butler, R. J., \& Johnson, W. G. (2008). Satisfaction with low back pain care. The Spine Journal, 8(3), 510-521

ACSQH. (2012). National safety and quality health service standards. Sydney: Australian Commission on Safety and Quality in Health Care.

Retrieved from http:// www.safetyandquality.gov.au/wpcontent/uploads/2011/09/NSQHSStandards-Sept-2012.pdf

Chang C-S, Chen S-Y, Lan Y-T. Service quality, trust, and patient satisfaction in interpersonal-based medical service encounters. BMC Health Serv Res 2013;13: 22-33.

Cooper K, Smith BH, Hancock E. Patient-centeredness in physiotherapy from the perspective of the chronic low back pain patient. Physiotherapy 2008;94:244-52.

Del Re AC, Flückiger C, Horvath AO, Symonds D, Wampold BE. Therapist effects in the therapeutic alliance-outcome relationship: A restricted-maximum likelihood meta-analysis. Clin Psych Rev 2012;32:642-49.

Desmeules F, Roy J-S, MacDermid JC, Champagne F, Hinse O, Woodhouse LJ. Advanced practice physiotherapy in patients with musculoskeletal disorders: a systematic review. BMC Musculoskelet Disord 2012;13:107-07.

Donabedian, A. Quality of care: how can it be assessed? JAMA 1988;260:1743-8.

Druss, B, Mechanic D. Should visit length be used as a quality indicator in primary care? Lancet 2003;361:1148 .

Edmondston, S., Waters, S Timms, R and Yates P. (2011). Impact of the inter-professional team approach in the development of person-centered health care within an orthopaedic out-patient clinic The International Journal of Person Centered Medicine 1(3), 1-5. 
Freeman, M., Gemignani, M., Benozzo, A., Brinkmann, S., \& Cisneros Puebla, C. A. (2014). Qualitative Inquiry and the Self-Realization of Psychological Science. Qualitative Inquiry, 20(2), 119-126.

Hall A, Ferreira P, Maher CG, J. Latimer J, Ferreira M. The Influence of the therapist-patient relationship on treatment outcome in physical rehabilitation: A systematic review. Phys Ther 2010;90:1099-110.

Hall, J. A., \& Dornan, M. C. (1990). Patient sociodemographic characteristics as predictors of satisfaction with medical care: A meta-analysis. Social Science \& Medicine, 30(7), 811818.

Hall MA, Camacho F, Dugan E, Balkrishnan R. Trust in the medical profession: conceptual and measurement issues. Health Serv Res 2002;37:1419-39.

Hall MA, Dugan E, Zheng B, Mishra AK. Trust in physicians and medical institutions: what is it, can it be measured, and does it matter?" Milbank Q 2001;79: 613-39.

Hills R. Kitchen S. Toward a theory of patient satisfaction with physiotherapy: exploring the concept of satisfaction. Physio Theory Prac, 2007;235: 243-54.

Hills, R., \& Kitchen, S. (2007a). Development of a model of patient satisfaction with physiotherapy. Physiotherapy Theory and Practice, 2007, Vol.23 (5), p.255-271.

Hills, R., \& Kitchen, S. (2007b). Satisfaction with outpatient physiotherapy: Focus groups to explore the views of patients with acute and chronic musculoskeletal conditions. Physiotherapy Theory and Practice, 2007, Vol.23(1), p.1-20, 23(1), 1-20.

Hojat M, Louis DZ, Maxwell K, Markham F, Wender R, Gonnella JS. Patient perceptions of physician empathy, satisfaction with physician, interpersonal trust, and compliance. Int $\mathbf{J}$ Med Educ 2010;1:83-87.

Hudak PL, Wright JG. The characteristics of patient satisfaction measures. Spine 2000;25:3167-77.

Hush JM, Cameron K, Mackey M. Patient satisfaction with musculoskeletal physical therapy care: a systematic review. Phys Ther 2011;91: 25-36.

Kelm Z, Womer J, Walter J, Feudtner C. Interventions to cultivate physician empathy: a systematic review. BMC Med Educ 2014;14: 219-30.

Kennedy DM, Robarts S, Woodhouse L. Patients are satisfied with advanced practice physiotherapists in a role traditionally performed by orthopaedic surgeons. Physiother Can 2010 62: 298-305.

Klitzman R. "Patient-time", "doctor-time", and "institution-time": perceptions and definitions of time among doctors who become patients. Patient Educ Couns 2007;66:147-55. 
Knight PK, Cheng AN.-J, Lee GM. Results of a survey of client satisfaction with outpatient physiotherapy care. Physiother Theory Prac 2010;26:297-307.

Kong MF, Camacho S, Feldman R, Anderson RT, Balkrishnan R. Correlates of patient satisfaction with physician visit: differences between elderly and non-elderly survey respondents. Health Qual Life Outcomes 2007;5:62-8.

Liamputtong, P. (2005). Qualitative research methods / Pranee Liamputtong and Douglas Ezzy (2nd Ed.). South Melbourne: South Melbourne: Oxford University Press.

McKinnon, A. L. (2001). Client Satisfaction with Physical Therapy Services. Physical \& Occupational Therapy in Geriatrics, 2001, Vol.19(2), p.23-37, 19(2), 23-37.

McMullen MN, Netland PA. Wait time as a driver of overall patient satisfaction in an ophthalmology clinic. Clin Ophthalmol 2013;7:1655-60.

Murray A, Hall A, Williams G, McDonough SM, Ntoumanis N, Taylor I, Jackson B, el al. Effect of a self-determination theory-based communication skills training program on physiotherapists' psychological support for their patients with chronic low back pain: randomized controlled trial. Arch Phys Med Rehabil 2015;96:809-16.

Napier C, McCormack RG, Hunt MA, Brooks-Hill A. A physiotherapy triage service for orthopaedic surgery: an effective strategy for reducing wait times. Physiother Can 2013;65:358-63.

Ng J, Ntoumanis N, Thogersen-Ntoumani C, Deci E, Ryan R, Duda J, et al. Selfdetermination theory applied to health contexts: a meta-analysis. Perspect Psychol Sci $2012 ; 7: 325-340$.

Noble PC, Conditt MA, Cook KF, Mathis KB. The John Insall Award: Patient expectations affect satisfaction with total knee arthroplasty. Clin Orthop Rel Res 2006;452:35-43.

Oldmeadow LB, Bedi HS, Burch HT, Smith JS, Leahy ES, Goldwasser M. Experienced physiotherapists as gatekeepers to hospital orthopaedic outpatient care. Med J Aust 2007;186:625-8.

Patton MQ. Qualitative Research \& Evaluation Methods / Michael Quinn Patton. 4th ed.. ed. Thousand Oaks, Calif.: Thousand Oaks, Calif. : Sage Publications; 2015

O’Reilly, M., \& Parker, N. (2013). 'Unsatisfactory Saturation': a critical exploration of the notion of saturated sample sizes in qualitative research. Qualitative Research, 13(2), 190197.

Perneger, T. (2004). Adjustment for patient characteristics in satisfaction surveys. International Journal for Quality in Health Care, 16(6), 433-435. 
Petty NJ, Thomson OP, Stew G. Ready for a paradigm shift? Part 2: Introducing qualitative research methodologies and methods. Man Ther 2012;17: 378-84.

Pollak KI, Alexander SC, Tulsky JA, Lyna P, Coffman CJ, Dolor RJ, et al. Physician empathy and listening: associations with patient satisfaction and autonomy. J Am Board Fam Med 2011 24: 665-72.

Powell RA, Single HM. Focus groups. Int J Qual Health Care 1996: 8: 499-504.

Rhodes P, Campbell S, Sanders C. Trust, temporality and systems: How do patients understand patient safety in primary care? A qualitative study. Health Expect 2015:Epub ahead of print.

Ryan RM, Deci EL. Self-determination theory and the facilitation of intrinsic motivation, social development, and well-being. Am Psychol 2005;5: 68-78.

Samsson K, Larsson MEH. Physiotherapy screening of patients referred for orthopaedic consultation in primary healthcare - A randomised controlled trial. ManTher 2014;19:38691.

Royal Australian College of Surgeons, Surgical Workforce Census Summary Report, 2011. https://www.surgeons.org/media/8789488rpt_2012-09-

10_2011_surgical_workforce_consus_report.pdf

Thompson AG, Suñol R. Expectations as determinants of patient satisfaction: concepts, theory and evidence. Int J Qual Health Care 1995;7:127-141.

Thomson OP, Petty NJ, Moore AP. Clinical decision-making and therapeutic approaches in osteopathy - A qualitative grounded theory study. Man Ther 201319: 44-51.

Trachtenberg F, Dugan E, Hall MA. How patients' trust relates to their involvement in medical care. J Fam Pract 2005 54: 344-52.

Ware EJ, Hays DR. Methods For Measuring Patient Satisfaction With Specific Medical Encounters. Medical Care. 1988;26(4):393-402.

Ware JE, Snyder MK, Wright WR, Davies AR. Defining and measuring patient satisfaction with medical care. Evaluation and Program Planning. 1983;6(3):247-263. 


\section{Table 1. Semi-structured interview guide}

The question structure was as follows:

We are interested in understanding patient satisfaction within the context of orthopedic triage settings. Can you offer any thoughts generally on patient satisfaction?

What factors do you believe contribute to patient satisfaction with clinical assessment?

What aspects of the relationship between the clinician and the patient are important?

Can you recall an experience as a patient at first assessment with a new clinician? What aspects of that experience would you like to improve or change?

What advice would you give to administrators of the health system to improve patient satisfaction in orthopedic clinics?

Table 2. Participant characteristics

\begin{tabular}{|c|c|c|c|c|c|c|c|c|}
\hline & Consultant & Physio & Nurse & Volunteer & CAC & Registrar & Patient & Reception \\
\hline Number & 4 & 4 & 5 & 3 & 5 & 4 & 10 & 1 \\
\hline $\begin{array}{c}\text { Interview } \\
\text { Method }\end{array}$ & $1: 1$ & Group & Group & Group & Group & $1: 1$ & $1: 1$ & $1: 1$ \\
\hline Male \% & 100 & 25 & 0 & 0 & 40 & 75 & 40 & 0 \\
\hline Female \% & 0 & 75 & 100 & 0 & 60 & 25 & 60 & 100 \\
\hline $\begin{array}{l}\text { Age range } \\
\text { (yrs) }\end{array}$ & $39-54$ & $28-62$ & $34-58$ & $64-78$ & $34-65$ & $28-34$ & $22-62$ & 32 \\
\hline \% of Total & 16 & 6 & 7 & 8 & 6 & 15 & 35 & 5 \\
\hline
\end{tabular}


Table 3. Characteristics of the Patient Focus Group.

Patient Focus Group Profile

\begin{tabular}{|c|c|c|c|}
\hline 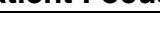 & Age & Sex & Diagnosis \\
\hline Patient 1 & 42 & $\mathrm{~m}$ & Osteoarthritic knee \\
\hline Patient 2 & 62 & $f$ & Shoulder impingement \\
\hline Patient 3 & 52 & $f$ & Shoulder instability \\
\hline Patient 4 & 24 & $\mathrm{~m}$ & Ankle inversion sprain \\
\hline Patient 5 & 22 & $f$ & Patellofemoral disorder \\
\hline Patient 6 & 28 & $\mathrm{~m}$ & Osteoarthritic knee \\
\hline Patient 7 & 50 & $f$ & Shoulder Rotator cuff \\
\hline Patient 8 & 34 & $\mathrm{~m}$ & Shoulder impingement \\
\hline Patient 9 & 82 & $f$ & Osteoarthritic knee \\
\hline Patient 10 & 42 & $f$ & Foot Pain \\
\hline Average & 43.8 & & \\
\hline Male & $40 \%$ & & \\
\hline Female & $60 \%$ & & \\
\hline
\end{tabular}


Table 4. Summary of theme representation across focus groups.

\begin{tabular}{|l|l|l|l|l|l|l|l|l|}
\hline & Consultant & Physio & Nurse & Volunteer & CAC & Registrar & Patient & Reception \\
\hline Clinical wait time & & & & & & & & \\
\hline Clinic time & & & & & & & \\
\hline Empathy & & & & & & & \\
\hline Communication & & & & & & \\
\hline Expectation & & & & & & & \\
\hline Trust & & & & & & & \\
\hline Relatedness & & & & & & & & \\
\hline
\end{tabular}

Legend:

A few references with acknowledgement of theme within narrative.

Multiple references and acknowledgement of theme within narrative.

Strong representation of theme with frequent repetition within group narrative.

Single reference or no reference within narrative 
Table 5: Summary of themes and narrative

\begin{tabular}{|c|c|}
\hline Theme & Narrative \\
\hline Clinical waiting time & $\begin{array}{l}\text { "I think the key things are how long they've waited to come in the } \\
\text { first time, how long they've been in the waiting room, because I } \\
\text { think it's very hard to have a satisfied patient who's sat there for } \\
\text { four hours before they've seen you, they're never satisfied." }\end{array}$ \\
\hline Clinical contact time & $\begin{array}{l}\text { "If you're feeling like you're rushed in and out, I don't think you } \\
\text { develop the trust as much. I don't think you feel like they're maybe } \\
\text { going to do the best work for you." }\end{array}$ \\
\hline Empathy & $\begin{array}{l}\text { "There was an issue being lifted off the emergency bed onto the } \\
\text { ward bed and it really, really hurt. The nurse said with all } \\
\text { orthopaedics it's nice if you have a small pain and it's hurting. It } \\
\text { was as if it didn't matter." }\end{array}$ \\
\hline Communication & $\begin{array}{l}\text { "I see a lot of patients privately for second opinions where I see a lot } \\
\text { of them where they've been given perfectly good advice. They've } \\
\text { actually had a perfectly good assessment in terms of advice and } \\
\text { treatment options. They're very unsatisfied with service they've had } \\
\text { because they haven't felt they've been communicated with or } \\
\text { listened to properly."[ }\end{array}$ \\
\hline Expectation & $\begin{array}{l}\text { "The GP who refers them may give them an unrealistic expectation } \\
\text { via we'll send you to the orthopod who will fix your problem, which } \\
\text { is rarely the case." }\end{array}$ \\
\hline Trust & $\begin{array}{l}\text { ".... and in reality the consent form is really a form that says I trust } \\
\text { you. The important part is chatting away and telling what the form is } \\
\text { really, basically I recognise that you know what you're doing and } \\
\text { you will try your best for me and in my circumstances you would be } \\
\text { doing the same." }\end{array}$ \\
\hline Relatedness & $\begin{array}{l}\text { "And you've got that connection because you put your trust in him } \\
\text { when you had the operation. But then you get this other guy who } \\
\text { you've never seen before to assess the leg. It's like you're in the } \\
\text { process with the public system." }\end{array}$ \\
\hline
\end{tabular}

